\title{
REVIEW
}

\section{Can cell therapy heal a spinal cord injury?}

\author{
MW Ronsyn ${ }^{1,2}$, ZN Berneman ${ }^{2,3}$, VFI Van Tendeloo ${ }^{2,3}$, PG Jorens ${ }^{1,2}$ and P Ponsaerts ${ }^{2,3}$ \\ ${ }^{1}$ Division of Clinical Pharmacotherapy, University of Antwerp, Antwerp, Belgium; ${ }^{2}$ Centre for Cell Therapy and Regenerative \\ Medicine, Antwerp University Hospital, University of Antwerp, Antwerp, Belgium and ${ }^{3}$ Laboratory of Experimental Hematology, \\ Vaccine and Infectious Disease Institute (VIDI), University of Antwerp, Antwerp, Belgium
}

\begin{abstract}
Study design: Literature survey.
Objectives: To summarize and discuss current possibilities and success rates for the treatment of spinal cord injury in animal models.

Settings: University of Antwerp, Belgium.

Methods: We searched Pubmed for publications from 1997 onwards. Seven older papers were used for completion of data.

Results: Despite major progress in pharmacological and surgical approaches, a spinal cord injury still remains a very complex medical and psychological challenge, both for the patients and their relatives, as well as for the involved physicians, with currently no existing curative therapy. For a future efficient treatment, one has to consider and combine four main approaches: (1) tissue or cell transplantation, (2) providing growth-stimulating factors (neurotrophic factors), (3) blocking factors which inhibit neural regeneration and (4) modulation of inflammatory response following spinal cord injury.

Conclusions: Although different treatment options have proven to be successful in animal models, they also provide a realistic view on a complex therapeutical approach, which needs to be further investigated in many carefully designed animal studies before human applications can be considered. Spinal Cord (2008) 46, 532-539; doi:10.1038/sc.2008.13; published online 18 March 2008
\end{abstract}

Keywords: spinal cord injury; cell transplantation; neurotrophic factors; endogenous neural regeneration; inflammation; clinical trials

\section{Introduction}

Despite major progress in pharmacological and surgical approaches, a spinal cord injury still remains a very complex medical and psychological challenge, both for patients and their relatives, as well as for involved physicians, with currently no curative therapy. The enormous impact, both in an individual-familial context, as well as on a broader socio-economical scale, is partly due to the young mean age (33 years) of the predominantly male (4:1 male/female ratio) patient population. ${ }^{1}$ Moreover, the life-long supportive care to prevent several complications (for example, decubitus, respiratory tract and urinary infections) means a substantial financial burden for both the patients and for the society.

The pathophysiological mechanism of a spinal cord injury is more than a simple mechanical disruption or contusion of

Correspondence: Dr M Ronsyn, Division of Pharmacotherapy, University of Antwerp, Universiteitsplein 1, Antwerp B-2610, Belgium.

E-mail: mark.ronsyn@ua.ac.be or

Professor P Ponsaerts, Laboratory of Experimental Hematology, Vaccine and Infectious Disease Institute (VIDI), University of Antwerp, Universiteitsplein 1, Antwerp B-2610, Belgium.

E-mail: peter.ponsaerts@ua.ac.be

Received 11 September 2007; revised 12 November 2007; accepted 22 November 2007; published online 18 March 2008 certain nerve tracts. It must be considered as a multi-step cascade in which the primary lesion, causing the direct disruption of nerve tracts (due to contusion, laceration, penetration, etc.), is progressively extended during the following hours, days and weeks by a massive inflammatory reaction, mainly consisting of influx of peripheral inflammatory cells (macrophages, T-cells) and activation of resident microglia. This secondary damage, accompanied by ischemia, edema, hemorrhage and cytotoxicity, will finally result in the formation of glial scar tissue surrounding a central cavitation on the site of the initial trauma in the spinal cord. The latter is known to act as an important physical and chemical barrier for endogenous regeneration of ascending and descending nerve tracts, thereby compromising functional outcome (Figure 1). In this context, the final functional outcome will depend on the extent of remaining myelinated nerve tracts, which is associated with the magnitude of both the primary and the secondary damage.

Taking into account, the abovementioned multi-step process, with the importance of secondary damage and the old dogma of the absence of neural regeneration in the 


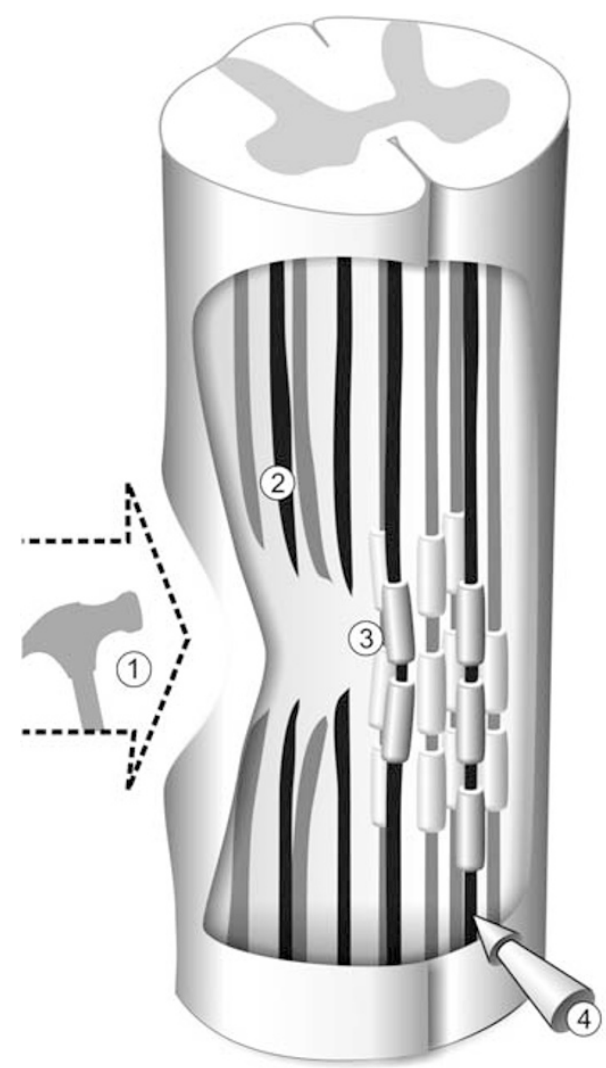

Acute stage:

1. Direct impact

2. Lacerated axons

3. Contused axons

4. Influx of inflammatory cells

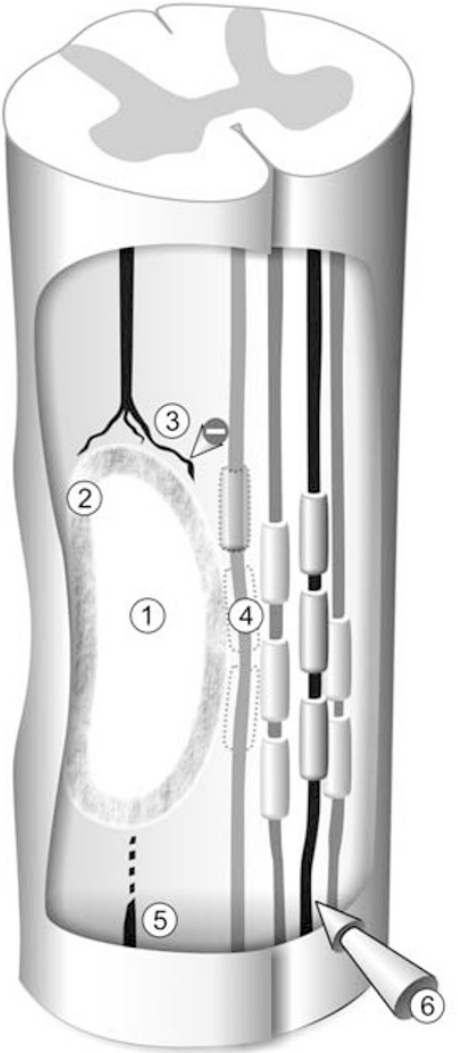

Chronic stage:

1. Central cavity

2. Scar tissue

3. Inhibition of axonal regeneration

4. Demyelination

5. Axonal dieback

6. Influx of inflammatory cells

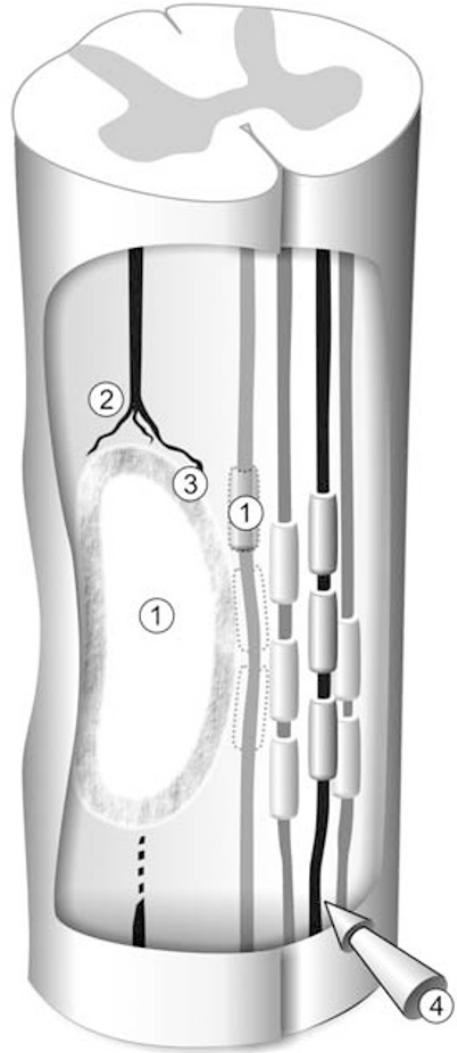

Treatment options:

1. Cell-, tissue transplantation

2. Blocking inhibition of axonal regrowth

3. Enhancing axonal regeneration

4. Modulating inflammatory

responses

Figure 1 Schematic presentation of the pathophysiological process of a spinal cord injury in the acute and the chronic stage with the different treatments options indicated.

central nerve system, the current therapeutic intervention in the acute setting is, since long, mainly focussed on prevention and restriction of secondary inflammatory responses. This is currently achieved by: (i) decompression of the spinal cord by laminectomy to limit ischemia, and/or orthopaedic fixation of the involved vertebrae to limit extra damage by bone pieces and (ii) administration of high doses of steroids (methylprednisolone; National Acute Spinal Cord Injury (NASCI)-scheme) in the acute post-injury phase to limit edema formation. ${ }^{2}$ The latter therapy is, however, not considered as evidence based by a large part of the medical and scientific world.

Currently, the existence of endogenous mechanisms for neural regeneration in the central nerve system is on the way of becoming more and more generally accepted. The latter is demonstrated in multiple animal studies showing the presence of neural stem cells in different areas of the brain. In addition, in vitro and in vivo differentiation capacity of these neural stem cells into neural cells types (neurons, oligodendrocytes and astrocytes) has been shown extensively. This finding has recently been confirmed in humans by Uchida et al., ${ }^{3}$ who documented the existence of adult neural stem cells in the subventricular zones of the brain, opening the way toward possible curative therapies for spinal cord injury in humans.

During the last decade, multiple attempts in animal models of spinal cord injury have investigated different underlying pathophysiological mechanisms to develop therapies able to prevent secondary damage and to enhance endogenous regeneration. Briefly, these approaches are focussed on (i) replacement of damaged neural tissue, (ii) enhancement of endogenous neural regeneration (by providing neurotrophic factors or by blocking growth-inhibiting signals) and (iii) modulation of the inflammatory response after spinal cord injury (Figure 1). The aim of this review is to give a brief overview of present successful therapeutic approaches described in animal models of spinal cord injury.

\section{Cell and tissue transplantation}

A key element in restoring function after a spinal cord injury through cell transplantation will be the replacement of damaged neural tissue (neurons, oligodendrocytes) to re-establish connections between central and peripheral nervous system. In this context, successful results were 
obtained with different cell types: embryonic stem cells, adult neural stem cells, fetal tissue, myelin-producing cells and mesenchymal stem cells (MSCs).

McDonald et al. ${ }^{4}$ differentiated murine embryonic stem cells into neural progenitor cells and transplanted these cells in a rat model of spinal cord injury. Their results showed in vivo survival, migration and neural differentiation of these cell transplants. Moreover, cell-treated animals had significant better motor recovery as compared to a control group. However, in another study, tumor formation was seen in a part of the animals transplanted with embryonic stem cells despite the obtained neurological improvement. ${ }^{5}$

Transplantation of adult neural stem cells isolated post mortem out of human brains was associated with extensive remyelination, morphologically comparable with the myelination pattern of Schwann's cells in the peripheral nervous system, when transplanted in demyelinated rat spinal cords. ${ }^{6}$ These experiments by Akiyama et al. also showed, besides the above described morphological resemblance, almost normal conduction velocities by electrophysiological analysis, indicating the functionality of the newly produced myelin. In addition, others ${ }^{7}$ reported improved weight support after transplantation of murine neural stem cells, embedded in a polymer scaffold, in a hemisection model in rat. However, this functional benefit was not believed to be due to cell differentiation, but was linked to a decrease in glial scar tissue and significantly less tissue loss by secondary damage, hereby sparing nerve tracts.

Axonal growth was seen in transplants of fetal tissue combined with neurotrophic factors, emphasising the possible role of these growth factors (see below). This histologically demonstrable neural regeneration resulted in improved motor recovery. Surprisingly, postponing the transplantation up to $2-4$ weeks post-injury resulted in a significantly better outcome, suggesting an important influence of post-injury inflammatory responses on survival and integration of transplanted cells/tissue. ${ }^{8}$

Novel axonal growth toward a cell transplant could also be achieved by transplanting polymer-guiding channels with Schwann's cells (myelin-producing cells from the peripheral nerve tissue) into a spinal cord injury model. Again, electrophysiological analysis suggested proper electrophysiological function of newly grown axons. ${ }^{9}$

Despite all above-described successful cell-therapy experiments, it should be noted that under physiological conditions, allogeneic cell transplantation, independently of cell type, will be associated with immunological rejection unless proper immune suppression is provided. Therefore, to circumvent this problem of immunological rejection, MSCs, non-hematopoeitic stem cells residing in the bone marrow, have received much attention nowadays. Indeed, such MSCs can be cultured relatively easily out of a bone marrow aspirate and have shown in vitro trans-differentiation potential into neural cells. ${ }^{10}$ After transplantation into brain and spinal cord, differentiation of MSCs into cells with neuronal and astrocyte characteristics was reported. ${ }^{11}$ Transplantation in demyelinated spinal cord resulted in proper remyelination, associated with enhanced conduction velocity, $^{12}$ suggesting that cell transplantation might cause an influence through integration and/or differentiation of transplanted cells, but also by a possible paracrine effect, which can alter the local environment allowing for endogenous regeneration. However, caution is needed as some recent reports describe in vivo tumor formation after MSC transplantation. ${ }^{13,14}$ Indeed, we also observed intraspinal tumor formation upon transplantation of genetically modified bone marrow-derived stromal cells in rat spinal cord (unpublished results).

Next to MSCs, olfactory ensheating cells (OEC), a glial cell type, which plays an important role in the lifelong neural regeneration capacity of olfactory neurons, hold great promise for potential clinical application. OECs can be extracted in a simple and reliable manner from olfactory mucosa. OEC transplantation following spinal cord injury resulted in significantly improved recovery, both motor and sensory, and was shown to result in neo-angiogenesis by production of vascular endothelial growth factor (VEGF) (see below). ${ }^{15}$ These results are encouraging regarding future clinical application, not only due to the relative ease with which they can be obtained by a minimally invasive manner (extraction by a swab from the olfactory mucosa), but also in view of their autologous nature, which makes them at least as good for therapeutic cell transplantations as MSCs.

In conclusion, multiple studies provide evidence for the use of cell transplants (embryonic stem cells, adult stem cells and adult myelinating cell types) in an approach to heal spinal cord injury. However, in most of these studies, the mechanisms leading to functional improvement following cell transplantation still remain to be elucidated. The fact that the use of different cell types results in similar improvement in functional outcome indicates that the underlying mechanism does not solely depend on the cell type itself, but could possibly rely on a broader mechanism, in which paracrine influences on the local environment cannot be excluded. This understanding led to the concept that cell transplantation cannot be fully successful without the application of other factors to modulate the injury site to create a more permissive environment for neural regeneration. Of major importance are the above-described results using MSCs and olfactory ensheating cells bringing cell transplantation, as part of a new therapeutic approach for spinal cord injury, to a more realistic level, given the importance of autologous cell transplantation to avoid immune-mediated rejection.

\section{Neurotrophic factors}

Key proteins in neurogenesis are the different members of the family of neurotrophic factors, which are mainly produced by glial cells residing in the central and peripheral nervous system. Brain-derived neurotrophic factor, neurotrophin-3 (NT-3), nerve growth factor and glial cell-derived neurotrophic factor are shown to be significantly elevated (up to 10 times) in day 10 postnatal murine brain as compared to the adult brain. This can easily be explained by ongoing axonal outgrowth, an extremely active process during this early postnatal period. The decrease in mRNA 
expression afterwards, associated with significant lower protein levels, results in a substantial fall in axonal regenerative capacity. In a therapeutic context, application (either direct by pumps or indirect by modulated cells) of brain-derived neurotrophic factor or NT-3 following a spinal cord injury resulted in in vivo enhancement of neural regeneration, often associated with improved functional outcome.

Implantation of a NT-3-secreting collagen matrix ${ }^{16}$ on the site of a spinal cord injury resulted in a substantial increase in the number of regrowing corticospinal axons as compared to implantation of a vehicle-loaded collagen matrix. An important observation, however, was the absence of any regenerated axon distally from the implantation site, indicating that axonal regrowth was limited towards the direction of an NT-3 source. Similar experimental outcomes were obtained by implanting NT-3-releasing guidance channels after trans-section of the dorsal $\operatorname{root}^{17}$ or by the local application of brain-derived neurotrophic factor by the use of viral vectors. ${ }^{18}$ In addition, the positive effects of fetal tissue transplantation, described in the abovementioned study of Coumans et al., ${ }^{8}$ was also thought to be mainly due to secretion of neurotrophic factors by the transplanted cells and not to the cells themselves. The same mechanism seems to be a key player in the positive outcome of neural stem cell transplantation following a spinal cord injury, namely their physiological secretion of neurotrophic factors (nerve growth factor, brain-derived neurotrophic factor and glial cell-derived neurotrophic factor), which can be significantly augmented by additional genetic modification of these cells with NT-3, again stressing the regenerative potential of these growth factors. ${ }^{19}$

Although guidance channels, osmotic pumps, collagens, hydrogels and so on are all possible delivery methods to administer neurotrophic factors, in vivo clinical application is far from realistic due to the possible side-effects associated with implantation of foreign bodies, which can indeed result in extra stimulation of inflammatory responses in an already compromised spinal cord. Therefore, much attention is now given to the use of autologous cell transplants (for example, fibroblasts and MSCs) as carriers of neurotrophic factors. The therapeutic potential of this approach has been demonstrated in multiple studies using genetically modified cell transplants. ${ }^{20}$ However, stable long-term gene expression in vivo is still an important issue and needs to be further optimalized. $^{21}$

Regarding all above-described studies, the exact contribution to the observed functional and histological improvements of a spinal cord injury by, on the one hand, the 'cells' and, on the other hand, the 'neurotrophic factors' is still not completely clear. However, the results are encouraging enough to further develop this research strategy.

Next to the above-described neurotrophic factors, VEGF, a potent angiogenic factor, has also been shown to have neuroregenerative capacities both in the central and in the peripheral nervous system. ${ }^{15,22}$ Special interest for VEGF originates in the proven strong association between low VEGF levels and the presence of amyotrophic lateral sclerosis, both in human and in rodents. ${ }^{23} \mathrm{~A}$ few publications report positive effects of VEGF after spinal cord contusion and trans-section with an enhanced functional outcome, a decline in apoptosis, a tissue-sparing effect and a decrease in retrogradual degeneration of corticospinal axons. ${ }^{22}$ However, prudence is warranted in view of reports of increased secondary damage following spinal cord injury when giving VEGF therapy. The latter can be explained by increased neoangiogenesis followed by an increase in influx of inflammatory cells. ${ }^{24}$

Altogether, it becomes more and more clear that the key elements in future treatment for spinal cord injury will not only be to provide new cells or tissue, but also to modulate the environment to make it more supportive and permissive for endogenous neural regeneration. Neurotrophic factors, as shown in multiple animal studies, can play a key role in this modulation.

\section{Blocking inhibitors of neural regeneration}

For years, it was believed that neural regeneration did not occur in the central nervous system of mammals. Currently, this dogma is more and more left behind due to welldocumented observations describing the possibility of neural regeneration under in vitro conditions and in in vivo settings. However, despite the existence of neural regeneration, in an injured spinal cord, this regeneration is effectively blocked by myelin and glial scar tissue. ${ }^{25,26}$ It has indeed been demonstrated that myelin contains multiple growth-inhibiting factors, among which Nogo-A is one of the most potent ones. Administration of antibodies directed against Nogo-A to spinal cord-injured rats resulted in improved functional outcome. ${ }^{27}$ In addition, Nogo-A could also be demonstrated in human spinal cord and similar promising results on functional recovery were found in a trial where spinal cordinjured marmoset monkeys were treated with anti-Nogo-A antibodies, making human therapeutic application more realistic. ${ }^{28,29}$ Another possibility for therapeutic intervention can be concluded from the analysis of the physiological working mechanism of myelin-associated proteins in younger and older postnatal neurons. Younger neurons, which are stimulated for axonal growth, show higher levels of cyclic adenosine monophosphate (cAMP) as compared to the same type of neurons of an older postnatal age, which show inhibition of axonal (re)growth. ${ }^{30}$ In this context, cAMP has inhibiting properties on myelin-associated glycoproteins and hereby possibly enhances neural regeneration. Increasing the level of cAMP in injured spinal cord by local application of cAMP or by inhibiting phosphodiesterase (which degrades cAMP) resulted in functionally and histologically demonstrable neural regeneration in rats. ${ }^{31}$ Next to the abovedescribed direct inhibitory signals, a negative influence on neural regeneration is also ascribed to rho-GTPase, an intracellular regulator of the cytoskeleton. Inhibition of rho or rho-associated kinase resulted both in in vitro and in vivo enhancement of neural regeneration, although, in vivo, mainly corticospinal axons were sensitive to this therapeutic approach. In addition, analysis of the motor cortex of mice following treatment with a rho inhibitor or a rho-kinase 
inhibitor showed an increase in mRNA of growth-associated protein-43, an indication of neural regeneration. ${ }^{32}$

Next to inhibition of neural regeneration by myelinassociated proteins, a second major inhibitor is glial scar tissue by itself. Activation of astrocytes is an important phase during secondary inflammatory responses in injured spinal cord and is associated with changes in the extracellular matrix. Chondroitin sulfate proteoglycans are an important component of this extracellular matrix and have a substantial inhibitory effect on endogenous regeneration. ${ }^{33}$ Degradation by chondroitinase resulted in significant decrease of cavity formation, decline in gliosis and increase in regeneration of ascending and descending pathways resulting in significant improvement of motor recovery. ${ }^{34}$

Although cell therapy and neurotrophic factors have been shown to be major therapeutic candidates for restoring the injured spinal cord, outgrowth of new axons is likely to be less successful without also acting against inhibitory glial scar formation and extracellular matrix proteins.

\section{Modulation of inflammatory responses}

Next to direct loss of neuronal cells and inhibition of axonal outgrowth, inflammatory responses are the third main component of the complex pathophysiology of a spinal cord injury, leading to its dysfunctional outcome. As mentioned above, inflammatory reactions start immediately following injury and play a crucial role in the pathophysiology of a spinal cord injury and, hereby, also determine the final functional outcome. However, it must be seen as a dualedged sword, where destructive and constructive effects are brought about by the same cells, with enhancement and blocking of axonal regeneration simultaneously. Immediately after a central nervous system injury, a temporary damage of the blood-brain/blood-spinal cord barrier occurs, leading to an active influx of peripheral immune cells. These cells further worsen the initial damage by demyelination of remaining intact axons, which is followed by loss of conduction capacity due to necrosis and apoptosis of oligodendrocytes. In a next phase, residual glial cells become activated and migrate towards the site of injury. Initially, they will promote endogenous regeneration by producing neurotrophic factors. However, outgrowing axons will be chemically and physically blocked by the formation of a glial scar (formed mainly by astroglial cells), which surrounds the injured area. The importance of these inflammatory processes is also demonstrated by the fact that the only pharmacological approach nowadays to treat spinal cord injuries is the use of methylprednisolone to reduce edema and inflammation and thereby reducing secondary inflammatory damage.

Several research strategies in animal models are currently focussing on how to exploit the constructive effects of inflammation and at the same time to avoid the destructive effects. In this context, animal studies demonstrated that systemic administration of interleukin-10, a potent anti-inflammatory cytokine capable of inhibiting the inflammatory reactions of monocytes and macrophages in the peripheral nervous system and capable of inhibiting the production of tumor necrosis factor- $\alpha$ by astrocytes in the central nervous system, significantly enhanced functional recovery after spinal cord injury and resulted in a 50\%reduction in lesion volume, 2 months post-injury. ${ }^{35}$ Also, depletion of peripheral macrophages following spinal cord injury resulted in an increase in motor function post-injury and a decrease in cavity formation. The latter again demonstrates the negative role of macrophages on the outcome of a spinal cord injury, probably due to (in)direct destruction of intact nerve tissue and regrowing axons. ${ }^{36}$

In addition to direct inhibition of inflammatory responses, influencing downstream processes was also demonstrated to have impact on histological and functional outcome. Apoptotic cell death of glial cells results in an important demyelination following a spinal cord injury. ${ }^{37}$ Key element in this apoptotic process is the interaction between tumornecrosis factor receptor complex and CD95-ligand. Blockage of this apoptotic pathway by cycloheximide (a protein synthesis inhibitor) or by neutralization of CD95-ligand resulted both in significant tissue sparing and was associated with improved functional outcome. ${ }^{38}$ Also, blockage of a non- $N$-methyl-D-aspartate-receptor (receptor of excitatory amino acids) resulted in improved outcome. The latter demonstrates the importance of cell necrosis induced by exo-cytotoxicity (due to elevated concentrations of excitatory amino acids, for example, glutamate) in addition to apoptotic processes. ${ }^{39}$

In conclusion, despite the above-described successful results, much more research will be needed to fully understand ongoing inflammatory processes, both site- and timedependent. In this way, an approach should be developed, which allows to support the positive elements of post-injury inflammatory reactions, and at the same time to decrease the detrimental effects, and this in combination with cell transplantation, neurotrophic factors and inhibition of scar tissue formation.

\section{Lessons from and for human clinical trials}

Today, the only accepted, although more and more questioned, therapy for spinal cord injury in humans is the use of high doses of methylpredisolone. This therapy was introduced after positive results of the NASCI-II-trial, ${ }^{2}$ which demonstrated a significantly improved motoric and sensoric outcome when given in the first $8 \mathrm{~h}$ after injury.

Despite multiple successful animal experiments, where potential therapies interfere on different levels of the pathophysiology of spinal cord injury, only few human trials have been initiated, with in general disappointing results. Due to these negative results, almost no published literature exists on the outcome data of these trials. Recently, recommendations were brought forward by the International Campaign for Cures of Spinal Cord Injury Paralysis (ICCP) to propose standards for the conduct of clinical trials in spinal cord injury. ${ }^{40,41}$ A clear review of ongoing clinical trials and experimental case reports in humans is nicely presented by Schwab et al. ${ }^{42}$ 
Today, one of the largest bench-to-bedside advances is happening in the field of regenerative medicine, where human cell therapy clinical trials are set up in multiple medical fields, such as spinal cord injury, amyotrophic lateral sclerosis, Parkinson's disease, myocardial infarction, heart failure, diabetes mellitus, orthopedics and so on Although almost all these studies are phase I trials, exploring safety and feasibility, too much stress is put on a 'yes or no' answer regarding clinical outcome. By pursuing this point of view, one should not neglect the most important message of these trials, namely the absence in humans of acute or chronic side effects after autologous cell transplantation. The most advanced and the best designed cell therapy studies are the ones examining intracoronary and intramyocardial bone marrow-derived stem cell infusion in the acute and chronic setting of myocardial infarction as an additive therapy next to reperfusion techniques (coronary artery bypass surgery and percutaneous transluminal coronary angioplasty). ${ }^{43-45}$ However, the observed significant improvement in heart function (an increase in left ventricular ejection fraction and a decrease in left end-systolic volume) and the decrease in infarcted area, thus far has not been linked to transdifferentiation of the stem cells into cardiomyocytes, but is most likely due to improved angiogenesis, which is probably the result of transplanted endothelial cells and/or of the production of angiogenic factors. This raises the hope that a similar therapeutic strategy (paracrine effect by secretion of certain growth factors and/or increased angiogenesis) might become a useful approach to treat spinal cord injuries.

A very recent study, although not in humans, is noteworthy because of the possible application in the nearby future. Iwanami et al. ${ }^{46}$ transplanted human neural stem cells, derived from embryos, in the spinal cord of nonhuman primates after cervical spinal cord contusion. The transplanted human cells survived for at least 8 weeks (the end of the observation period), differentiated into neurons, astrocytes and oligodendrocytes and resulted in a significant enhancement of functional recovery, without any signs of tumor formation. These results clearly demonstrate beneficial possibilities of human stem cells in a primate study, which opens the door to possible human applications.

\section{Toward human clinical applications}

Although current therapeutic approaches for spinal cord injury are mainly focused on prevention and treatment of secondary complications, animal research has provided multiple successful strategies to follow to cure and not just to care for spinal cord injury. However, application of these promising therapeutic approaches will need much more research, both on the basic level to clear out the exact pathophysiological mechanism of secondary damage and endogenous regeneration, as well as on a more applied level of animal experimentation and translation into human clinical trials. A general approach to follow will consist of two major pathways: on the one hand, protecting the remaining intact nerve tissue against destructive effects of post-injury secondary responses and on the other hand, enhancement of existing endogenous neural regeneration. The only way to achieve this challenging goal will be through a combination of several strategies described in this review. For example, stem cell transplantation, without modulation of the aggressive post-injury environment, will have no sense regarding the detrimental influence of secondary inflammatory responses on regeneration. Another main issue will be the route of (stem) cell transplantation. Invasive procedures on a compromised spinal cord may worsen already existing inflammatory responses, especially if it is carried out in the acute post-injury setting. Therefore, future therapies should not only be focused on intraspinal cell transplantation, but also on an intrathecal and intravenous cell administration, which might avoid further aggravation of the injured spinal cord. In this context, encouraging results were presented in a study by Bakshi et al., ${ }^{47}$ who showed migration of intrathecally and intravenously injected bone marrow-derived stromal cells towards the site of injury. This observation, combined with the results found in the myocardial infarction trials ${ }^{43-45}$ raises the hope that transplantation by minimal invasive delivery (for example, intravenous or intrathecal) of autologous bone marrow-derived stromal cells can be tested in the nearby future in human clinical trials for spinal cord injury.

However, both patients and clinicians must agree that a perfect restoration of the original anatomy of the spinal cord may not be the ultimate aim at the moment. Indeed, restoration of a limited amount of nerve tracts can already have a dramatic impact on quality of life of a spinal cord patient. ${ }^{48}$ Walking again should not be the main objective, rather a normal bladder and bowel function and restored sexual function must be pursued. ${ }^{49}$ In addition, the only modest improvement of physical activity will be enough to have dramatic impact on general cardiovascular health of the patient and to prevent complications, such as decreased bone mineral content, decubitus and urological complications. $^{50}$

\section{Acknowledgements}

This research work is supported by research Grants 7.0004.03N (P Jorens) and WO.012.02.N (Z Berneman) of the Fund for Scientific Research-Flanders (FWO-Vlaanderen, Belgium), by research Grant 1081 BOF-KP 2005 (P Ponsaerts) from the Antwerp University and by the Fund for Cell Therapy ( $\mathrm{Z}$ Berneman and $\mathrm{P}$ Jorens) from the Antwerp University Hospital. Mark Ronsyn holds a PhD-fellowship of the FWO-Vlaanderen. Viggo FI Van Tendeloo and Peter Ponsaerts are postdoctoral fellows of the FWO-Vlaanderen.

\section{References}

1 Wyndaele M, Wyndaele JJ. Incidence, prevalence and epidemiology of spinal cord injury: what learns a worldwide literature survey? Spinal Cord 2006; 44: 523-529.

2 Bracken MB, Shepard MJ, Collins WF, Holford TR, Young W, Baskin DS et al. A randomized, controlled trial of methylprednisolone or naloxone in the treatment of acute spinal-cord injury. Results of the Second National Acute Spinal Cord Injury Study. N Engl J Med 1990; 322: 1405-1411. 
3 Uchida N, Buck DW, He D, Reitsma MJ, Masek M, Phan TV et al. Direct isolation of human central nervous system stem cells. Proc Natl Acad Sci USA 2000; 97: 14720-14725.

4 McDonald JW, Liu XZ, Qu Y, Liu S, Mickey SK, Turetsky D et al. Transplanted embryonic stem cells survive, differentiate and promote recovery in injured rat spinal cord. Nat Med 1999; 5: $1410-1412$

5 Riess P, Molcanyi M, Bentz K, Maegele M, Simanski C, Carlitscheck $\mathrm{C}$ et al. Embryonic stem cell transplantation after experimental traumatic brain injury dramatically improves neurological outcome, but may cause tumors. I Neurotrauma 2007; 24: 216-225.

6 Akiyama Y, Honmou O, Kato T, Uede T, Hashi K, Kocsis JD. Transplantation of clonal neural precursor cells derived from adult human brain establishes functional peripheral myelin in the rat spinal cord. Exp Neurol 2001; 167: 27-39.

7 Teng YD, Lavik EB, Qu X, Park KI, Ourednik J, Zurakowski D et al. Functional recovery following traumatic spinal cord injury mediated by a unique polymer scaffold seeded with neural stem cells. Proc Natl Acad Sci USA 2002; 99: 3024-3029.

8 Coumans JV, Lin TT, Dai HN, MacArthur L, McAtee M, Nash $\mathrm{C}$ et al. Axonal regeneration and functional recovery after complete spinal cord transection in rats by delayed treatment with transplants and neurotrophins. J Neurosci 2001; 21: 9334-9344.

9 Pinzon A, Calancie B, Oudega M, Noga BR. Conduction of impulses by axons regenerated in a Schwann cell graft in the transected adult rat thoracic spinal cord. J Neurosci Res 2001; 64: 533-541.

10 Jiang Y, Jahagirdar BN, Reinhardt RL, Schwartz RE, Keene CD, Ortiz-Gonzalez XR et al. Pluripotency of mesenchymal stem cells derived from adult marrow. Nature 2002; 418: 41-49.

11 Lee J, Kuroda S, Shichinohe H, Ikeda J, Seki T, Hida K et al. Migration and differentiation of nuclear fluorescence-labeled bone marrow stromal cells after transplantation into cerebral infarct and spinal cord injury in mice. Neuropathology 2003; 23: 169-180.

12 Akiyama Y, Radtke C, Kocsis JD. Remyelination of the rat spinal cord by transplantation of identified bone marrow stromal cells. I Neurosci 2002; 22: 6623-6630.

13 Liu C, Chen Z, Chen Z, Zhang T, Lu Y. Multiple tumor types may originate from bone marrow-derived cells. Neoplasia 2006; 8: 716-724.

14 Tolar J, Nauta AJ, Osborn MJ, Panoskaltsis MA, McElmurry RT, Bell S et al. Sarcoma derived from cultured mesenchymal stem cells. Stem Cells 2007; 25: 371-379.

15 Lopez-Vales R, Garcia-Alias G, Fores J, Navarro X, Verdu E. Increased expression of cyclo-oxygenase 2 and vascular endothelial growth factor in lesioned spinal cord by transplanted olfactory ensheathing cells. J Neurotrauma 2004; 21: 1031-1043.

16 Houweling DA, Lankhorst AJ, Gispen WH, Bar PR, Joosten EA. Collagen containing neurotrophin-3 (NT-3) attracts regrowing injured corticospinal axons in the adult rat spinal cord and promotes partial functional recovery. Exp Neurol 1998; 153: 49-59.

17 Bloch J, Fine EG, Bouche N, Zurn AD, Aebischer P. Nerve growth factor- and neurotrophin-3-releasing guidance channels promote regeneration of the transected rat dorsal root. Exp Neurol 2001; 172: 425-432.

18 Kwon BK, Liu J, Lam C, Plunet W, Oschipok LW, Hauswirth W et al. Brain-derived neurotrophic factor gene transfer with adenoassociated viral and lentiviral vectors prevents rubrospinal neuronal atrophy and stimulates regeneration-associated gene expression after acute cervical spinal cord injury. Spine 2007; 32: $1164-1173$

$19 \mathrm{Lu}$ P, Jones LL, Snyder EY, Tuszynski MH. Neural stem cells constitutively secrete neurotrophic factors and promote extensive host axonal growth after spinal cord injury. Exp Neurol 2003; 181: 115-129.

20 Cao Q, Xu XM, Devries WH, Enzmann GU, Ping P, Tsoulfas P et al. Functional recovery in traumatic spinal cord injury after transplantation of multineurotrophin-expressing glial-restricted precursor cells. J Neurosci 2005; 25: 6947-6957.
21 Rosenqvist N, Hård Af Segerstad C, Samuelsson C, Johansen J, Lundberg C. Activation of silenced transgene expression in neural precursor cell lines by inhibitors of histone deacetylation. J Gene Med 2002; 4: 248-257.

22 Facchiano F, Fernandez E, Mancarella S, Maira G, Miscusi M, D'Arcangelo D et al. Promotion of regeneration of corticospinal tract axons in rats with recombinant vascular endothelial growth factor alone and combined with adenovirus coding for this factor J Neurosurg 2002; 97: 161-168.

23 Lambrechts D, Storkebaum E, Morimoto M, Del Favero J, Desmet F, Marklund SL et al. VEGF is a modifier of amyotrophic lateral sclerosis in mice and humans and protects motoneurons against ischemic death. Nat Genet 2003; 34: 383-394.

24 Benton RL, Whittemore SR. VEGF165 therapy exacerbates secondary damage following spinal cord injury. Neurochem Res 2003; 28: 1693-1703.

25 GrandPre T, Strittmatter SM. Nogo: a molecular determinant of axonal growth and regeneration. Neuroscientist 2001; 7: 377-386.

26 Yiu G, He Z. Glial inhibition of CNS axon regeneration. Nat Rev Neurosci 2006; 7: 617-627.

27 Bregman BS, Kunkel-Bagden E, Schnell L, Dai HN, Gao D, Schwab ME. Recovery from spinal cord injury mediated by antibodies to neurite growth inhibitors. Nature 1995; 378: 498-501.

28 Fouad K, Klusman I, Schwab ME. Regenerating corticospinal fibers in the Marmoset (Callitrix jacchus) after spinal cord lesion and treatment with the anti-Nogo-A antibody IN-1. Eur J Neurosci 2004; 20: 2479-2482.

29 Prinjha R, Moore SE, Vinson M, Blake S, Morrow R, Christie G et al. Inhibitor of neurite outgrowth in humans. Nature 2000; 403: 383-384.

30 Cai D, Qiu J, Cao Z, McAtee M, Bregman BS, Filbin MT. Neuronal cyclic AMP controls the developmental loss in ability of axons to regenerate. J Neurosci 2001; 21: 4731-4739.

31 Nikulina E, Tidwell JL, Dai HN, Bregman BS, Filbin MT. The phosphodiesterase inhibitor rolipram delivered after a spinal cord lesion promotes axonal regeneration and functional recovery. Proc Natl Acad Sci USA 2004; 101: 8786-8790.

32 Dergham P, Ellezam B, Essagian C, Avedissian H, Lubell WD McKerracher L. Rho signaling pathway targeted to promote spinal cord repair. J Neurosci 2002; 22: 6570-6577.

33 Tan AM, Zhang W, Levine JM. NG2: a component of the glial scar that inhibits axon growth. $J$ Anat 2005; 207: 717-725.

34 Bradbury EJ, Moon LD, Popat RJ, King VR, Bennett GS, Patel PN et al. Chondroitinase $\mathrm{ABC}$ promotes functional recovery after spinal cord injury. Nature 2002; 416: 636-640.

35 Bethea JR, Nagashima H, Acosta MC, Briceno C, Gomez F, Marcillo AE et al. Systemically administered interleukin-10 reduces tumor necrosis factor-alpha production and significantly improves functional recovery following traumatic spinal cord injury in rats. J Neurotrauma 1999; 16: 851-863.

36 Popovich PG, Guan Z, Wei P, Huitinga I, van Rooijen N, Stokes BT. Depletion of hematogenous macrophages promotes partial hindlimb recovery and neuroanatomical repair after experimental spinal cord injury. Exp Neurol 1999; 158: 351-365.

37 Casha S, Yu WR, Fehlings MG. Oligodendroglial apoptosis occurs along degenerating axons and is associated with FAS and p75 expression following spinal cord injury in the rat. Neuroscience 2001; 103: 203-218.

38 Demjen D, Klussmann S, Kleber S, Zuliani C, Stieltjes B, Metzger $\mathrm{C}$ et al. Neutralization of CD95 ligand promotes regeneration and functional recovery after spinal cord injury. Nat Med 2004; 10: 389-395.

39 Wrathall JR, Teng YD, Choiniere D. Amelioration of functional deficits from spinal cord trauma with systemically administered NBQX, an antagonist of non- $N$-methyl-D-aspartate receptors. Exp Neurol 1996; 137: 119-126.

40 Lammertse D, Tuszynski MH, Steeves JD, Curt A, Fawcett JW, Rask $\mathrm{C}$ et al. Guidelines for the conduct of clinical trials for spinal cord injury as developed by the ICCP panel: clinical trial design. Spinal Cord 2007; 45: 232-242.

41 Steeves JD, Lammertse D, Curt A, Fawcett JW, Tuszynski MH, Ditunno JF et al. Guidelines for the conduct of clinical trials for 
spinal cord injury (SCI) as developed by the ICCP panel: clinical trial outcome measures. Spinal Cord 2007; 45: 206-221.

42 Schwab JM, Brechtel K, Mueller CA, Failli V, Kaps HP, Tuli SK et al. Experimental strategies to promote spinal cord regeneration - an integrative perspective. Prog Neurobiol 2006; 78: 91-116.

43 Britten MB, Abolmaali ND, Assmus B, Lehmann R, Honold J, Schmitt J et al. Infarct remodeling after intracoronary progenitor cell treatment in patients with acute myocardial infarction (TOPCARE-AMI): mechanistic insights from serial contrast-enhanced magnetic resonance imaging. Circulation 2003; 108: 2212-2218.

44 Schachinger V, Erbs S, Elsasser A, Haberbosch W, Hambrecht R, Holschermann $\mathrm{H}$ et al. Intracoronary bone marrow-derived progenitor cells in acute myocardial infarction. $N$ Engl $J$ Med 2006; 355: 1210-1221.

45 Wollert KC, Meyer GP, Lotz J, Ringes-Lichtenberg S, Lippolt P, Breidenbach $\mathrm{C}$ et al. Intracoronary autologous bone-marrow cell transfer after myocardial infarction: the BOOST randomised controlled clinical trial. Lancet 2004; 364: 141-148.

46 Iwanami A, Kaneko S, Nakamura M, Kanemura Y, Mori H, Kobayashi S et al. Transplantation of human neural stem cells for spinal cord injury in primates. J Neurosci Res 2005; 80: 182-190.

47 Bakshi A, Hunter C, Swanger S, Lepore A, Fischer I. Minimally invasive delivery of stem cells for spinal cord injury: advantages of the lumbar puncture technique. I Neurosurg Spine 2004; 1: 330-337.

48 Fehlings MG, Tator $\mathrm{CH}$. The relationships among the severity of spinal cord injury, residual neurological function, axon counts, and counts of retrogradely labeled neurons after experimental spinal cord injury. Exp Neurol 1995; 132: 220-228.

49 Anderson KD. Targeting recovery: priorities of the spinal cord-injured population. J Neurotrauma 2004; 21: 1371-1383.

50 Stotts KM. Health maintenance: paraplegic athletes and nonathletes. Arch Phys Med Rehabil 1986; 67: 109-114. 